
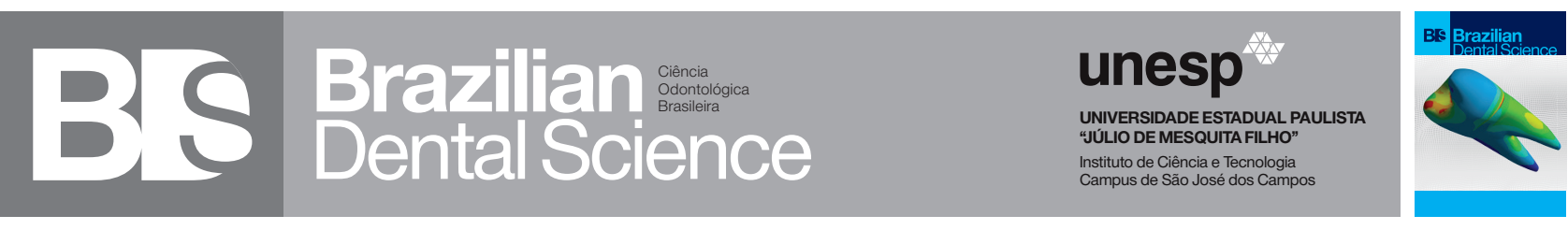

\title{
New fabrication method using additive manufacturing technologies for the pattern of pressed lithium disilicate onlay restorations
}

Novo método de fabricação, usando tecnologia aditiva, do padrão de restaurações do tipo onlay em dissilicato de lítio injetado

Marta REVILLA-LEON ${ }^{1}$, Marina OLEA-VIELBA ${ }^{2}$, Ana ESTESO-SAIZ ${ }^{3}$, Iñaki MARTINEZ-KLEMM ${ }^{4}$, José Manuel REUSS RODRIGUEZVILABOA ${ }^{5}$, Mutlu ÖZCAN ${ }^{6}$

1 - Revilla Research Center, Madrid, Spain and Affiliate Faculty Graduate Prosthodontics, School of Dentistry, University of Washington, USA.

2 - Private practice, Madrid Spain and Researcher at the Revilla Research Center, Madrid, Spain.

3 - Private practice, Madrid Spain and Researcher at the Revilla Research Center, Madrid, Spain.

4 - Dental Laboratory Odoteck, Madrid, Spain, Researcher at the Revilla Research Center, Madrid, Spain.

5 - Private practice and Affiliate Faculty Graduate in Prosthodontics, Complutense University of Madrid, Spain.

6 - University of Zurich, Division of Dental Materials, Center for Dental and Oral Medicine, Clinic for Fixed and Removable Prosthodontics and Dental Materials Science, Zurich, Switzerland.

\begin{abstract}
The digital workflow in dentistry allows for complete digital processing of the restoration starting with the digital impression using an intraoral scanner to until the fabrication of final reconstruction. Recent advances in 3D printing technologies opened new possibilities also for dental technicians through which wax-up and casting procedures in the laboratories could be eliminated. In this clinical report, a technique is described where the pattern was fabricated using additive manufacturing for pressed lithium disilicate onlay restorations.
\end{abstract}

\section{KEYWORDS}

3D printing; Additive manufacturing technologies; Castable printed pattern; Digital dentistry; Direct Light Processing; Lithium disilicate; Polymer printed; Stereolithography.

\section{RESUMO}

O fluxo de trabalho digital em odontologia permite o processamento digital completo da restauração começando com a impressão digital usando um scanner intraoral até a fabricação da peça final. Os avanços recentes nas tecnologias de impressão 3D abriram novas possibilidades também para os técnicos em prótese dentária através dos quais os procedimentos de cera e fundição nos laboratórios poderiam ser eliminados. Neste relato de caso clínico, descreve-se uma técnica onde o padrão foi fabricado usando a fabricação de aditivos para restaurações do tipo onlay em dissilicato de lítio injetadas.

\section{PALAVRAS-CHAVE}

Impressao 3D; Tecnologias de fabricação de aditivos; Padrões impressos; Odontologia digital; Processamento de luz direta; Dissilicato de lítio; Polímero impresso; Estereolitografia.

\section{INTRODUCTION}

$\begin{array}{ccc}\text { omputer } & \text { aided manufacturing } \\ \text { technologies } & \text { (CAM) are based on }\end{array}$ milling or additive manufacturing (AM) where in the latter an object is fabricated through layer-by-layer building process [1]. The American Society for Testing and Materials (ASTM) have determined seven AM categories, namely stereolithography (SLA), material jetting $(\mathrm{MJ})$, material extrusion or fused deposition modelling (FDM), binder jetting (BJ), powder 
bed fusion (PBF), sheet lamination (SL) and direct energy deposition (DEP) [1]. The most common technologies for $3 \mathrm{D}$ printing of polymers in the dental field are the SLA, MJ and FDM methods. Among these methods, in the SLA process, liquid photopolymer in a vat is selectively photo-polymerized layer by layer through a laser in order to create a 3D object $[2,3]$. The DLP technology on the other hand, is very similar to the SLA technology except form the light source as DLP uses a different light source, such as an arc lamp, with a liquid crystal display panel or a deformable mirror device (DMD) [4]. The MJ technology is based on a process where droplets of building material is deposited through hundreds of nozzles and photo-polymerized layer by layer using an ultraviolet light [5]. In the FDM technologies, the $3 \mathrm{D}$ printer extrudes a melting plastic filament that has been heated just beyond its melting point and is deposited one layer at a time onto a building platform according to the 3D data supplied to the printer. The heated material sets immediately after being extruded [6].

The rapid evolution of the market has positioned the 3D printing applications on the edge of the latest technologies in many industrial and medical fields. Yet, in dentistry, fairly limited numbers of applications are available and they have not been analyzed through, validated and systematically used for daily basic clinical procedures. The fundamental limitation is due to the restricted variety of biocompatible 3D printed materials approved for clinical dental applications by recognized organizations. However, some polymers could be used instead of wax or other resins for casting or pressing dental restorations and could be printed in conjunction with AM technologies [7-9]. One such example was the fabrication of the 3D pattern of the framework for the fabrication of a removable partial denture [10-12]. However, to the best of our knowledge, AM technologies has not been used to date for the fabrication of pressed ceramics.
In this clinical report, a technique has been described where the pattern was fabricated using AM technologies for pressed lithium disilicate onlay restorations.

\section{OUTLINE OF THE CASE}

A 38-year old male patient presented himself with the chief complaint related to a broken tooth. The patient presented healthy oral conditions. During the intraoral examination, fracture of the disto-lingual cusp and occlusodistal resin composite on the mandibular right first molar was noted (Figures 1a-c). The diagnostic radiographs showed root canal treatment (RCT) with periapical lesion and a deep interproximal restoration (Figure 2).
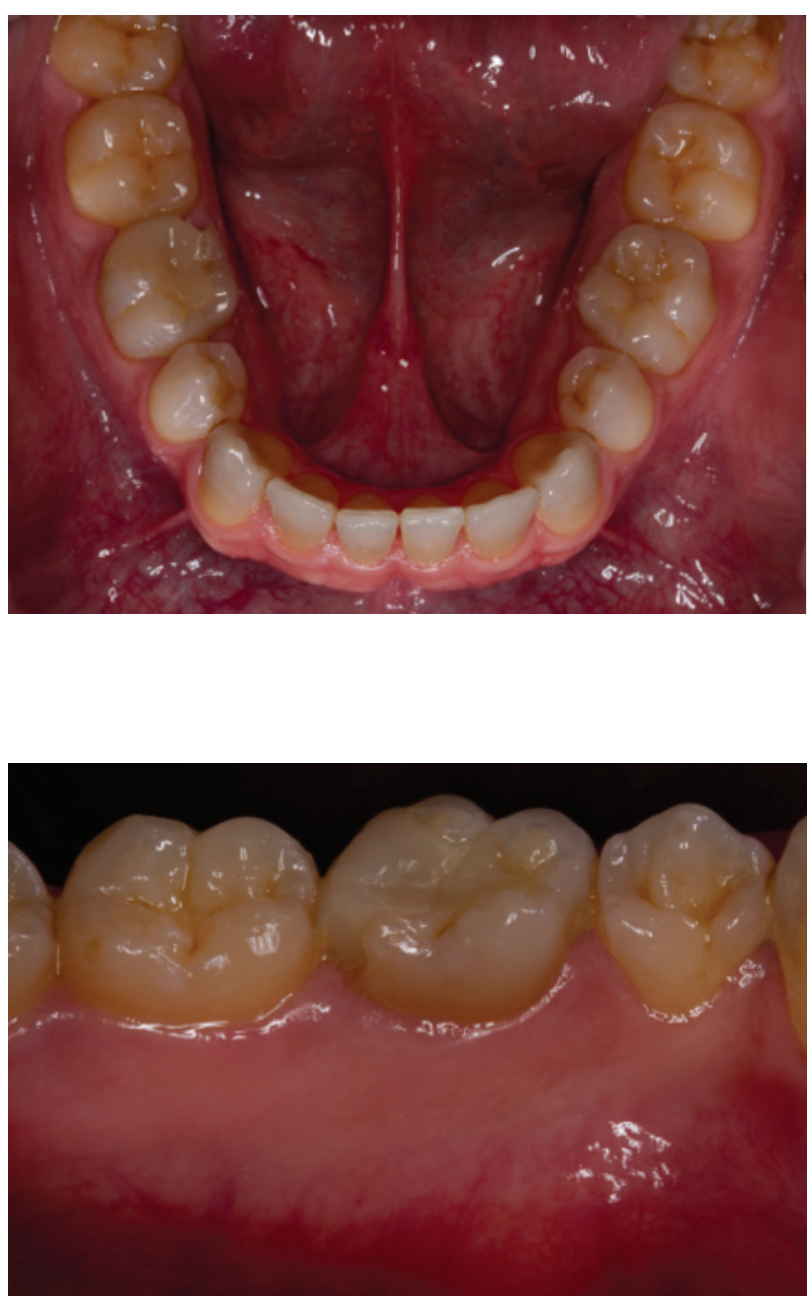


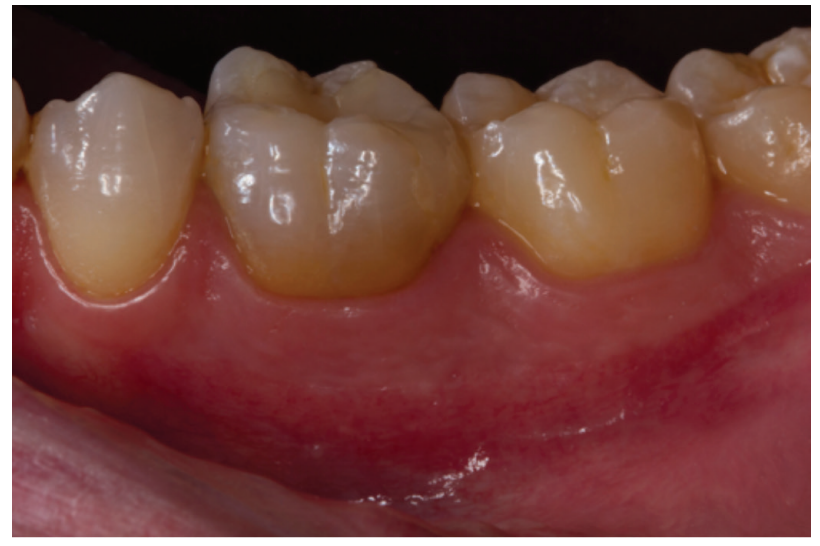

Figures 1 - a) Occlusal view of the intraoral situation with a cusp fracture on the mandibular right first molar, b) Lingual, c) Buccal view of the clinical situation

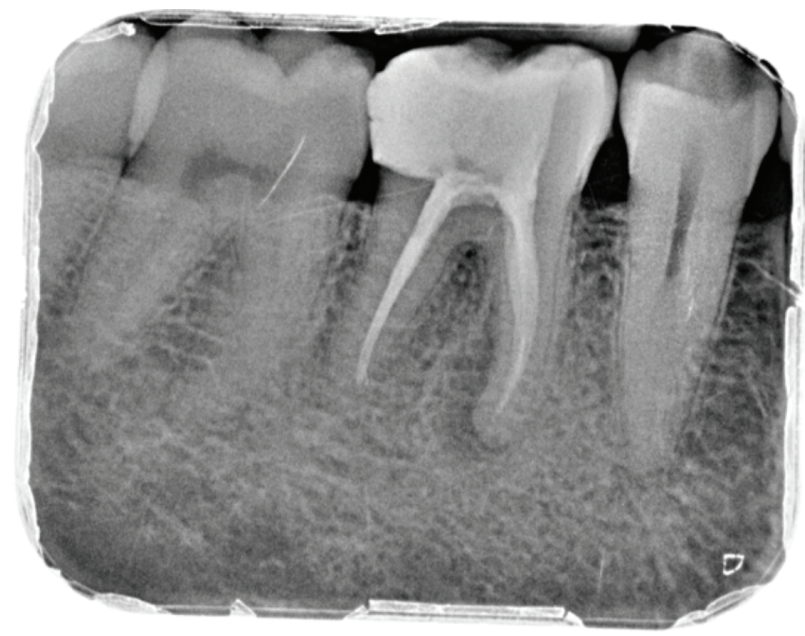

Figure 2 - Peri-apical radiograph of the mandibular right first molar

In order to evaluate the remaining tooth structure, resin composite restoration was removed. The disto-lingual cusp and the distal marginal border of the tooth were missing but the disto-buccal, mesio-buccal and mesio-lingual cusps presented sufficient thickness and adequate dentin support that did not necessitate cuspal coverage. Furthermore, the gingival floor of the cavity was located at the level of the bone crest.
Thus, crown lengthening along with retreatment of the RCT were indicated in order to restore the tooth in a predictable way [13-15]. Two specialists executed both procedures in a private (Figures 3,4). After complete healing, the tooth was restored with a pressed lithium disilicate onlay restoration as follows:

At the first clinical appointment, build up the tooth was accomplished using resin composite (Filtek Supreme XTE A3D, 3M ESPE, St. Paul, USA) in order to seal the canal opening after endodontic treatment and to provide enough support to the weak cusps that did not present dentin support.

Cavity was then prepared for an onlay restoration where the gingival floor of the preparation was located $0.5-1 \mathrm{~mm}$ above the gingival margin with $1 \mathrm{~mm}$ width and $2 \mathrm{~mm}$ isthmus reduction. Interocclusal space of 1.5. $\mathrm{mm}$ was provided for the restorative material and sharp internal angles were rounded using a roundended tapered diamond bur (8845KR.314.021 and 845KR.314.021, Komet Dental, Lemgo, Germany) under continuous water cooling. Margins of the preparation were outside the contact point with the antagonist (Figure 5).

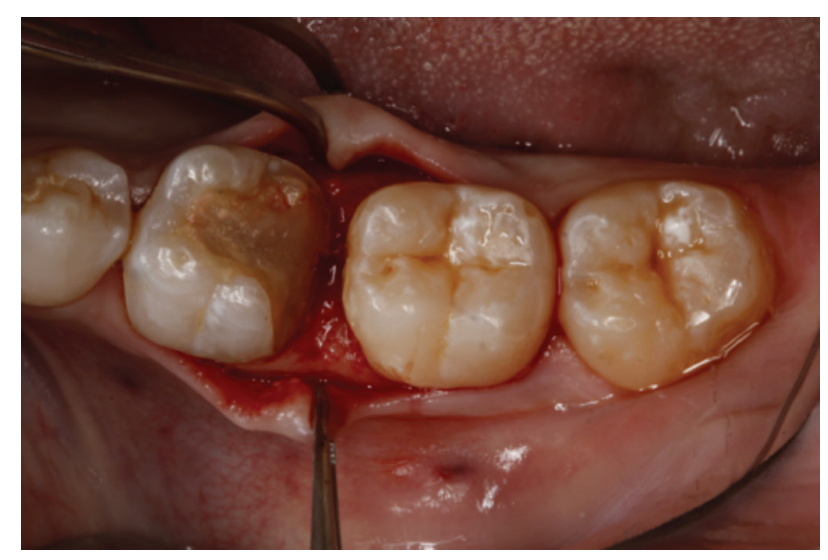

Figure 3 - Photo of crown lengthening procedure to reestablish the biological width 


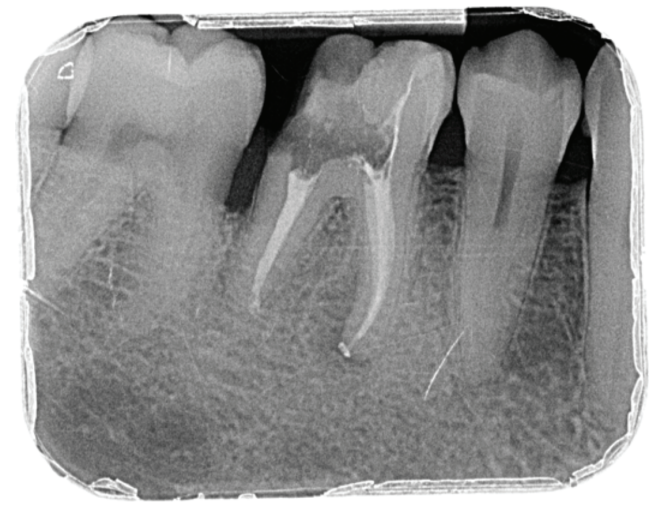

Figure 4 - Peri-apical radiograph of the tooth after root canal re-treatment and crown lengthening

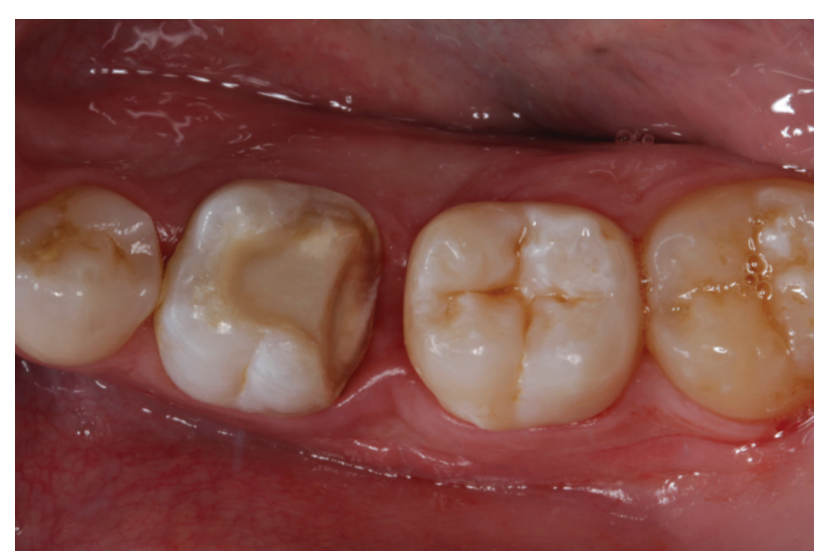

Figure 5 - Occlusal view of the onlay preparation on the mandibular right first molar

After preparation digital impression was made where the tooth preparation, the maxillary and mandibular arch and patient 's occlusion were scanned with an optical intraoral scanner (Trios 3Pod color, 3shape, Copenhagen, Denmark) following the manufacturer's instructions. Then a provisional restoration was fabricated using photo-polymerized provisional material (Fermit N, Ivoclar Vivadent, Schaan, Liechtenstein).

For the laboratory procedures and design of the onlay restoration, specific CAD software (Dental Sytem, 3Shape) was used. STL file of the digital onlay restoration was obtained (Figures 6ab) and sent to CAD specialized dental technician in a dental laboratory. Thereafter, using the STL file, polymer castable onlay restoration pattern (Visijet M3 DentCast, 3D Systems, Budel, Netherlands) was prepared using a multijet printer (Projet MJP 3600 Dental, 3D systems, Budel, Netherlands) at $15 \mu \mathrm{m}$ layer thickness (Figure 7 ). The production of the pattern started with CAM processing and followed by model fabrication and post processing the $3 \mathrm{D}$ object, which is specific to the technology and the printer used. The pattern was manufactured by a dental laboratory specialized in additive manufacturing technologies. CAM processing involves adding the supporting structures, specifying the build up variables and parameters for slicing the model on the computer to generate the information that controls the 3D printer. Model fabrication is based on building the object using the sliced file on the 3D printer. Afterwards, the build platform was inserted on the top of a cold blank plate inside of the fridge. Finally, the pattern was separated from the building plate of the 3D printer. Post-processing requires cleaning the object from physical and chemical bath to remove the supportive material and additional polymerization to complete the polymerization process. The printed object was placed in a non-metallic basket filled with $>99 \%$ isopropyl alcohol in the ultrasonic cleaner at $30^{\circ} \mathrm{C}$. When all the supportive material was completely dissolved, the pattern was removed from the cleaner and subjected to second ultrasonic cleaning in $>99 \%$ isopropyl alcohol. Finally, the pattern was removed and dried.

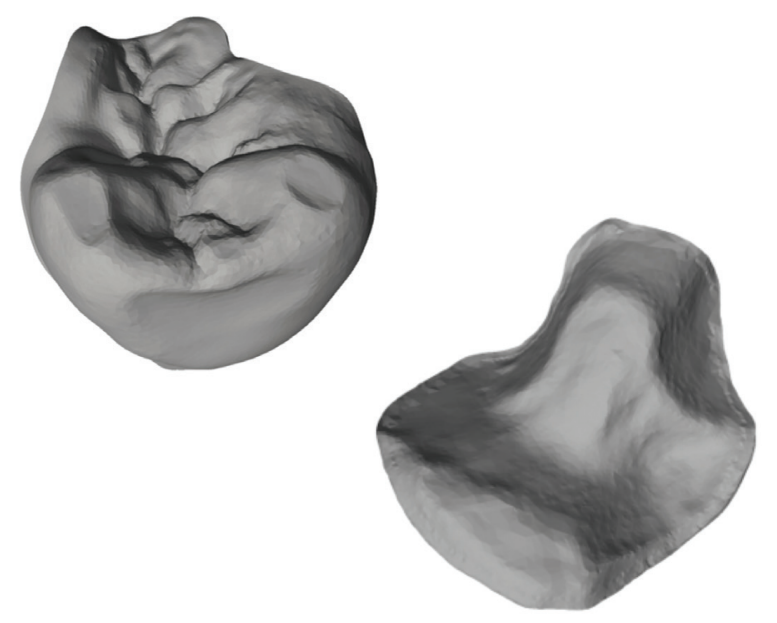

Figures 6 - a) Occlusal view and b) Intaglio surface of the digital design (STL file image) of the onlay restoration 

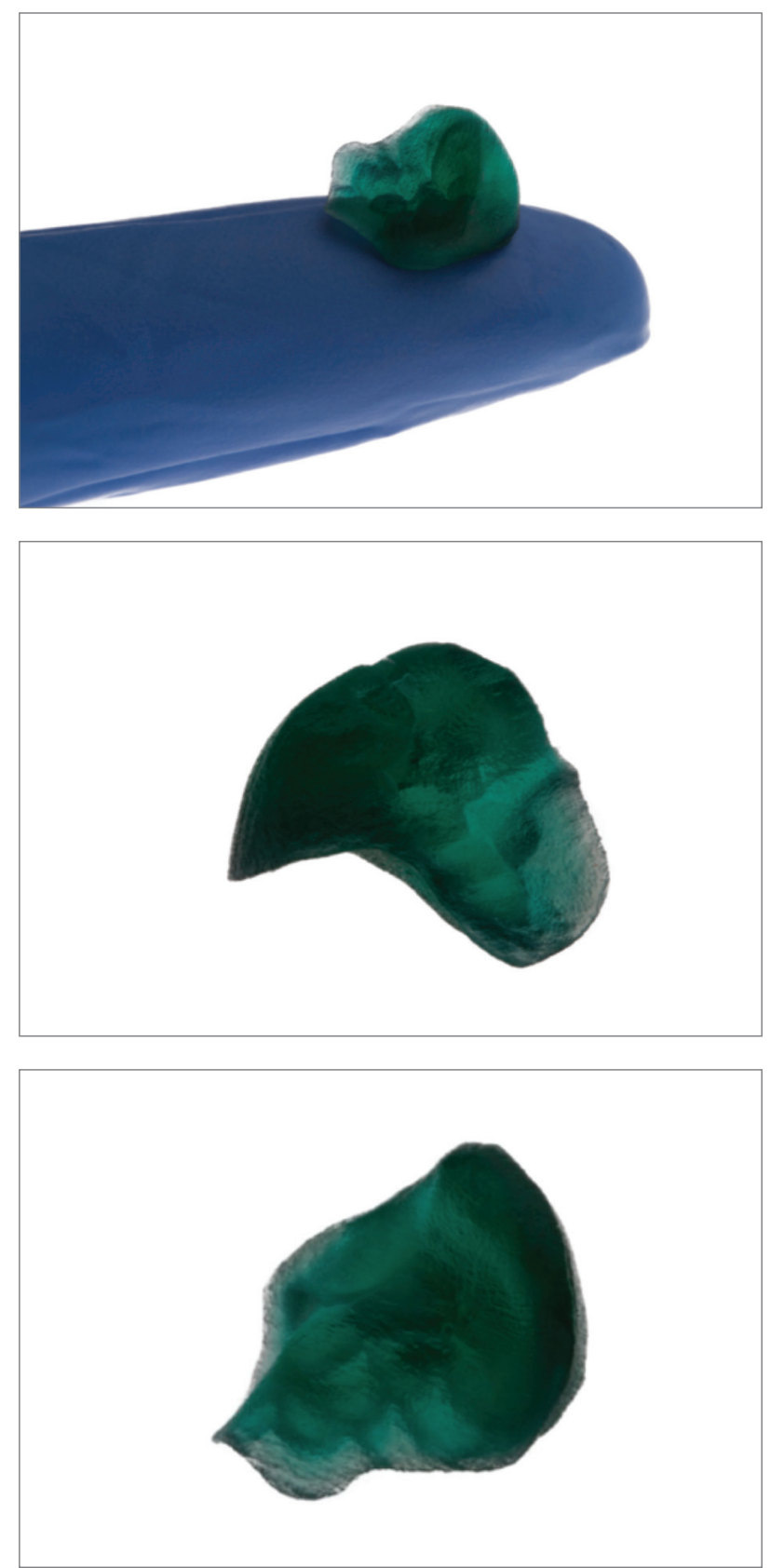

Figures 7 - Photos of a) castable 3D printed pattern of the onlay restoration, b) occlusal and c) intaglio surface

In order to press the 3D printed castable pattern, $10 \mathrm{~g}$ lead sprue was attached to the lingual surface of the pattern. According to the instructions of the manufacturer, the recommended length of the wax wire was 3-8 $\mathrm{mm}$ and 15-16 $\mathrm{mm}$ including the wax-up pattern and the angle between the ring base and the sprue was between $45-60^{\circ}$ (Figures 8ab). The pattern was invested (IPS PressVEST, Ivoclar Vivadent) following the manufacturer's recommendations as regards to powder/liquid ratio, vacuum mixture, mixing time and setting time (burn out temperature: $850^{\circ} \mathrm{C}, 1 \mathrm{~h}$ ). Then lithium disilicate ingot (LT A2 IPS Emax.Press, Ivoclar Vivadent) was pressed following the manufacturer's indications. After cooling to the room temperature for about 60 minutes, it was divested using a diamond disc to separate the plunger from the investment ring. Rough divesting was achieved using glass beads at 4 bar pressure and fine divesting was performed using reduced pressure of 2 bar preasure. The onlay restoration was placed in 5\% hydrofluoric acid (Invex Liquid IPS emax.Press, Ivoclar Vivadent) in a plastic cup for 15 minutes to remove the residues of $100 \mu \mathrm{m} \mathrm{Al} 2 \mathrm{O} 3$ at 1-2 bar pressure. The sprue was removed using a diamond bur and polished under water-cooling (Figures 9a-b).
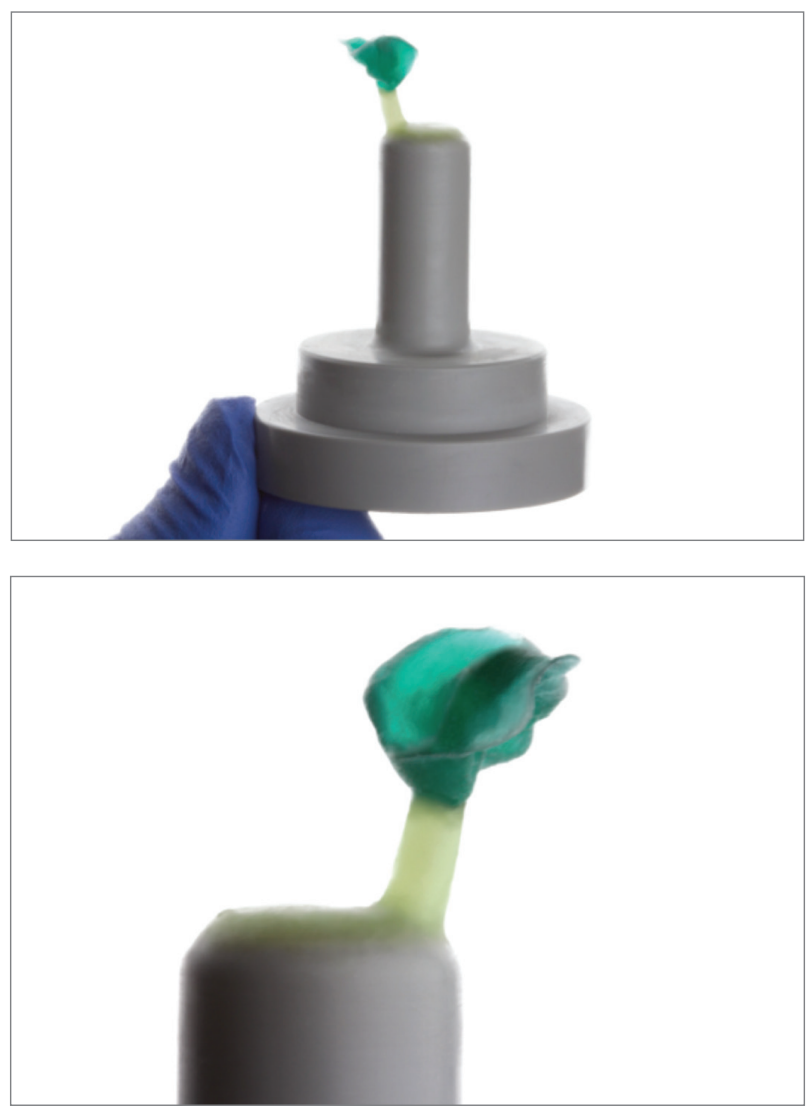

Figures 8 - Photos of a) sprued of the 3D printed castable pattern, b) intaglio and c) occlusal surface 
At the second clinical appointment, the onlay restoration was bonded to the tooth using dual-polymerized resin cement (Rely-X Lava Ultimate, 3M ESPE) following the manufacturer's instructions under rubber dam isolation (Figures 9c-d). After excess removal, the contact point was controlled using dental floss and verified that the contact to the neighbouring tooth was present and floss movement showed no interference. Finally,
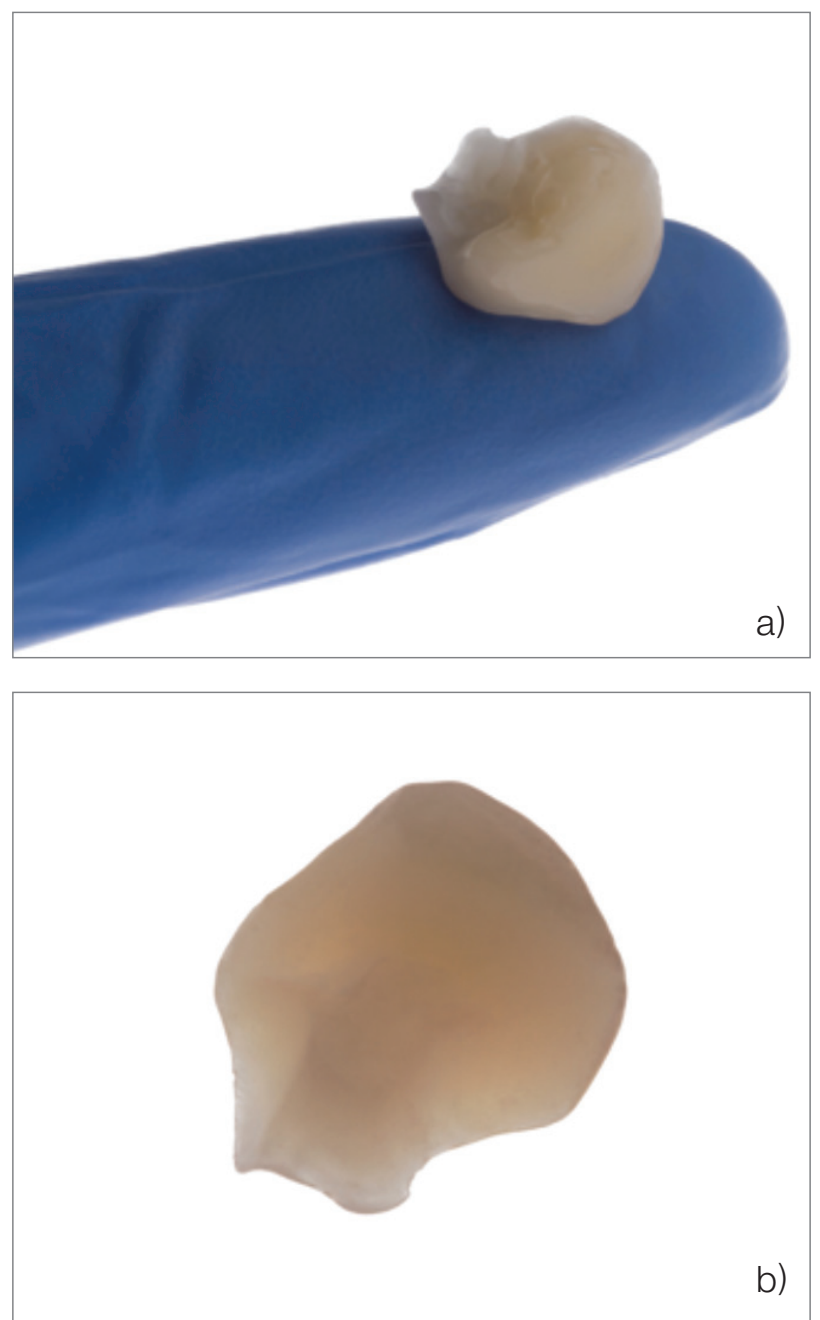

occlusion was controlled using $40 \mu \mathrm{m}$ articulator paper (Bausch Arti-Check articulating paper, Dr. Jean Bausch GmbH \& Co., Köln, Germany). Premature contact was not noted on disto-lingual cusp and removed using a bur (8368L.314.016 komet Dental). The onlay was then polished using specific lithium disilicate polishing burs (Astropol P, HP Ivoclar Vivadent).
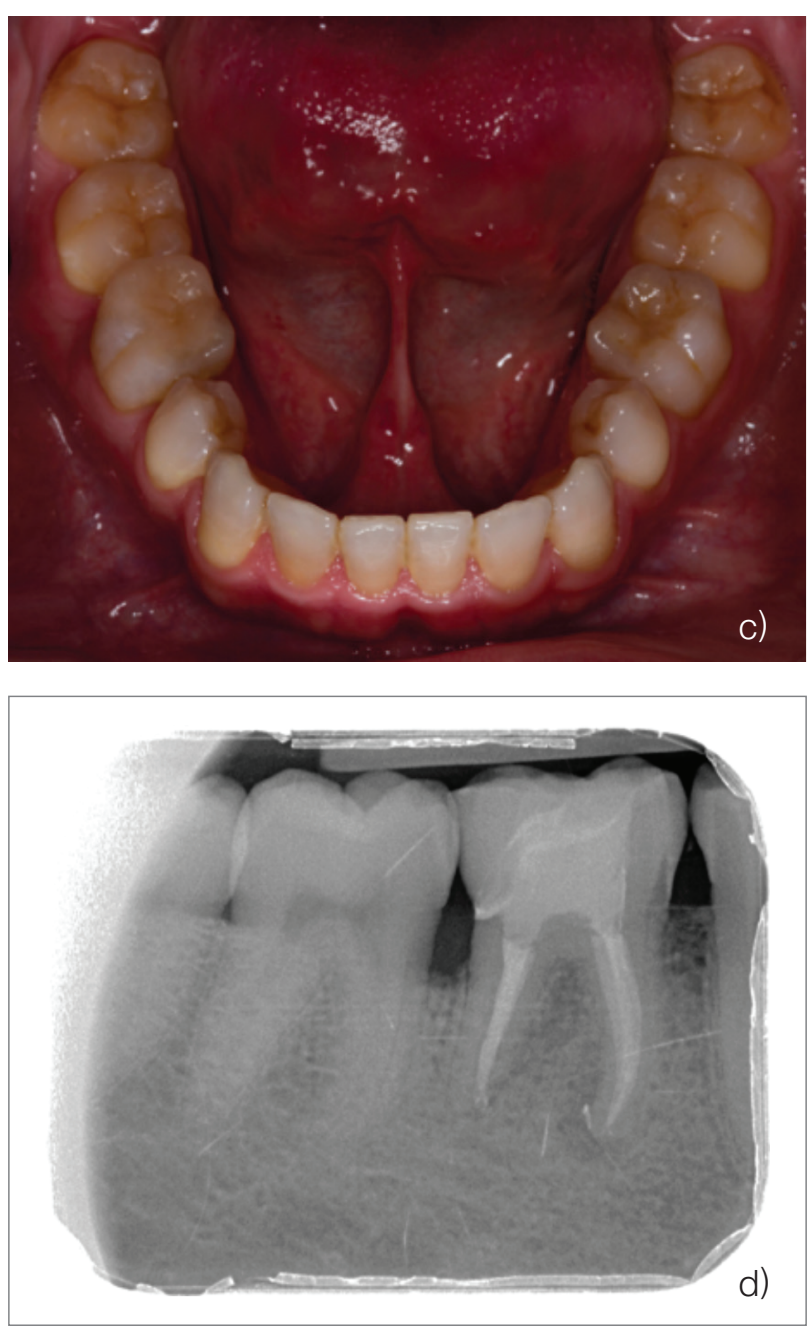

Figures 9 - Photos of a) pressed lithium disilicate only restoration after polishing, b) occlusal and the intaglio surface of the restoration, c) after cementation, d) peri-apical radiograph after delivery of the onlay 


\section{DISSCUSION}

Due to the advances in intraoral digital devices, dental softwares for the digital design of the restoration and the incorporation of $\mathrm{AM}$ technologies, complete digital workflow in dentistry both for clinicians and the dental technicians expanded through which conventional dental laboratory work could be minimized. In this clinical report, the pattern for an onlay restoration was fabricated using AM methods.

One important aspect compared to conventional wax-up procedures is the precision with AM methods. The accuracy and precision of these technologies could be affected by multiple factors such as layer thickness [16], number of layers needed [2], amount of supportive material [2], building direction of the 3D object [17] and the meticulousness of the post processing process. In a previous study, manufacturing tolerance of four polymers used for AM printers, showed accuracy results ranging between -61 and $92 \mu \mathrm{m}$ [18].

The intraoral digital devices and the AM technologies have to been considered as tools that help the clinicians to develop a treatment in a more efficient way. The intraoral scanner used in this study (TRIOS 3 Pod color, 3shape) allows the clinician to check the inter-occlusal space and the path of insertion of the tooth preparation. These features enable the clinician to perform the changes needed before the impression is sent to the dental laboratory. Such devices also improve the communication between the dental professionals. However, the clinical parameters and principles do not differ from the conventional ones, meaning that the tooth preparation needs to be performed and corrected where needed by the clinician. For the correct reproduction of the intaglio surface of the onlay restoration, the internal angles of the tooth preparation need to be rounded, as the AM technologies cannot reproduce curved surfaces precisely [19].

AM technologies could be considered more economical to fabricate castable patterns as they do not waste material [20-22], and no additional tools are required [22,23]. Furthermore, 3D printing allows for printing more than one pattern at a time. In this clinical report, only one onlay restoration was made which could have been also restored with indirect or direct resin composite where the latter require more skills of the clinician during build up. However, AM technologies may save time for the restoration of occlusal wear cases due to erosion where multiple occlusal onlays need to be made for the complete arch. Furthermore, AM technologies present certain advantages compared to milling procedures since during milling, the tool size and the tip of the milling bur limits the desired fit and final shape of the fabricated object especially at the occlusal and marginal aspects $[7,8,23]$. Thus, it may be reasonable to argue that AM technologies are capable of reproducing a more detailed occlusal anatomy of a printed pattern for the subsequent pressed lithium disilicate restoration. Yet, post processing adds time to the workflow and in that respect direct resin composites could still be considered more efficient especially for fabrication of single restorations.

\section{SUMMARY}

In this clinical report, a technique was described for the fabrication of a 3D printed castable pattern for lithium disilicate onlay restoration. 3D printed patterns could be an alternative to conventional handmade wax-up or milled patterns that also allows manufacturing complex occlusal anatomical surfaces.

\section{DISCLOSURE}

The authors claim to have no financial interest, either directly or indirectly, in the products or information presented in the article.

\section{REFERENCES}

1. ASTM, Committee F42 on Additive Manufacturing Technologies, West Conshohocken, Pa. 2009.

2. Hull CW; US Patent. Apparatus for production of three-dimensional objects by stereolithography. 4575330. 1986. 
3. 3Hull CW, Spence ST, Albert DJ, Smalley DR, Harlow RA, Steinbaugh P, Tarnoff HL, Nguyen HD, Lewis CW, Vorgitch TJ, Remba DZ. Method and apparatus for production of three-dimensional objects by stereolithography, US Patent. 5059359, 1991.

4. Groth C, Kravitz ND, Jones PE, Graham JW, Redmond WR. Three-dimensional printing technology. J Clin Orthod. 2014 Aug;48(8):475-85.

5. Stansbury JW, Idacavage MJ. 3D printing with polymers: Challenges among expanding options and opportunities. Dent Mater. 2016 Jan;32(1):54-64. doi: 10.1016/j.dental.2015.09.018.

6. Gibson I, Rosen DW, Stucker B. Additive Manufacturing Technologies: Rapid Prototyping to Direct Digital Manufacturing. New York: Ed Springer. 2010.

7. Azari A, Nikzad S. The evolution of rapid prototyping in dentistry: a review. Rapid Prototyping J. 2009;15(3):216-25.

8. Sun J, Zhang FQ. The application of rapid prototyping in prosthodontics. J Prosthodont. 2012 Dec;21(8):641-4. doi: 10.1111/j.1532-849X.2012.00888.x.

9. Cho SH, Chang WG. Mirror-image anterior crown fabrication with computer-aided design and rapid prototyping technology: A clinical report. J Prosthet Dent. 2013 Feb;109(2):75-8. doi: 10.1016/S00223913(13)60018-9.

10. Wu M, Tinschert J, Augthun M, Wagner I, Schädlich-Stubenrauch J, Sahm PR, Spiekermann H. Application of laser measuring, numerical simulation and rapid prototyping to titanium dental castings. Dent Mater. 2001 Mar;17(2):102-8.

11. Williams RJ, Bibb R, Rafik T. A technique for fabricating patterns for removable partial denture frameworks using digitized casts and electronic surveying. J Prosthet Dent. 2004 Jan;91(1):85-8.

12. Williams RJ, Bibb R, Eggbeer D, Collins J. Use of CAD/CAM technology to fabricate a removable partial denture framework. J Prosthet Dent. 2006 Aug;96(2):96-9.

13. Palomo F, Kopczyk RA. Rationale and methods for crown lengthening. J Am Dent Assoc. 1978 Feb;96(2):257-60.
14. Brägger U, Lauchenauer D, Lang NP. Surgical lengthening of the clinical crown. J Clin Periodontol. 1992 Jan;19(1):58-63.

15. Ribeiro FV, Hirata DY, Reis AF, Santos VR, Miranda TS, Faveri M, et al. Open-flap versus flapless esthetic crown lengthening: 12-month clinical outcomes of a randomized controlled clinical trial. J Periodontol. 2014 Apr;85(4):536-44. doi: 10.1902/jop.2013.130145.'

16. Pandey PM, Reddy NV, Dhande SG. Real time adaptive slicing for fused deposition modelling. Int J Mach Tool Manufac. 2003:43(1):61-71.

17. Alharbi N, Osman R, Wismeijer D. Effect of build direction on the mechanical properties of 3D printed complete coverage interim dental restorations. J Prosthet Dent. 2016 Jun;115(6):760-7. doi: 10.1016/j.prosdent.2015.12.002.

18. Brain M, Jimbo R, Wennenberg A. Production tolerance of additive manufactured polymeric objects for clinical applications. Dent Mater. 2016 Jul;32(7):853-61. doi: 10.1016/j.dental.2016.03.020.

19. Ide Y, Nayar S, Logan H, Gallagher B, Wolfaardt J. The effect of the angle of acuteness of additive manufactured models and the direction of printing on the dimensional fidelity: clinical implications. Odontology. 2017 Jan;105(1):108-115. doi: 10.1007/ s10266-016-0239-4.

20. Berman B. 3D printing: The new industrial revolution. Bus Horiz. 2012;55:155-62.

21. Van Noort $R$. The future of dental devices is digital. Dent Mater. 2012 Jan;28(1):3-12. doi: 10.1016/j.dental.2011.10.014.

22. Stansbury JW, Idacavage MJ. 3D printing with polymers: Challenges among expanding options and opportunities. Dent Mater. 2016 Jan;32(1):54-64. doi: 10.1016/j.dental.2015.09.018.

23. Abduo J, Lyons K, Bennamoun M. Trends in computer-aided manufacturing in prosthodontics: a review of the available streams. Int J Dent. 2014;2014:783948. doi: 10.1155/2014/783948.

\section{Dr. Marta Revilla León} (Corresponding address)

Calle Berlin 14

28922 Madrid-Spain 